\title{
La historia en el debate actual
}

\author{
María Alba Pastor \\ FACULTAD DE FILOSOFÍ Y LETRAS-UNAM
}

L os textos presentados en el Congreso Internacional "La historia a debate", publicados en tres volúmenes en $1995,{ }^{1}$ constituyen un compendio excepcional para realizar un balance de los problemas que enfrenta actualmente la historia. Desde muy diversos ámbitos regionales -sobre todo europeos y americanos- y desde distintos enfoques, Ios materiales aquí reunidos muestran los múltiples caminos por los que incursionan los historiadores, así como los usos, limitaciones y pronósticos de la ciencia de la historia.

Como en todo encuentro de expertos, en aquel congreso se puso de manifiesto una singular posición frente al oficio del historiador y una particular vista del mundo que, sintéticamente, podríamos calificar como críticas y comprometidas con los problemas de nuestros tiempos. En esta segunda

1 Barros, Carlos (comp.), Historia a debate, 3 vols. Santiago de Compostela, Historia a debate, 1995. Véase también Barros, Carlos y Carlos Aguirre Rojas (comps.), Historia a debate. América Latina. Santiago de Compostela, Historia a Debate, 1996. mitad del siglo $\mathrm{xx}$, pocas han sido las reuniones de historiadores que se inclinen por tal tendencia. Por el contrario, lo que predomina en los ámbitos académicos suele ser la dispersión de temáticas, los desniveles de profundidad, la justificación del estado de cosas y el temor a confrontar la conflictiva realidad que nos envuelve; rasgos por demás característicos de nuestra era posmoderna. Y aunque en este congreso no faltaron pronunciamientos en favor de las bondades de la fragmentación, el descriptivismo y las nuevas tecnologías de la comunicación como panacea, el sello más relevante se estampó en la denuncia de las carencias de la historiografia para hacerinteligible el pasado y en el combate por recuperar la función social crítica que le da sentido a la ciencia de la historia.

Todo esfuerzo por reseñar una obra está indudablemente cargado de intenciones. No podría ser de otra manera. Bajo este supuesto, y dado que el material a que nos referimos aborda un gran número de asuntos, destacaremos los puntos que nos parecen de mayor significación y nos referiremos a los que -según nuestro entender- 
constituyen los centros en torno a los cuales giraron, recurrentemente, los textos presentados en Santiago de Compostela y que ahora están listos para su consulta. ${ }^{2}$

En primer término, quisiéramos poner énfasis en la constante preocupación, plasmada en estos escritos, por el futuro de la ciencia de la historia y su conexión con el porvenir de la sociedad. Esta preocupación se acompaña de la crítica a la posmodernidad y de un acusado interés por analizar los efectos de la crisis epistemológica que ha traído consigo el derrumbe de las certidumbres sobre las cuales se construyeron los paradigmas estructuralistas y cuantitativistas de la segunda mitad de nuestro siglo. En segundo término, si bien en los textos se reconocen las recientes aportaciones de la historiografia, su vitalidad y su expansión cultural, también se subrayan sus limitaciones y, sobre todo, su incapacidad para colocar al pasado en el centro de la estructuración de la realidad social; asi como sus débiles modelos para comprender la complejidad de los conflictos humanos. En tercer término, en estos textos se perfilan las nuevas tendencias y se marcan los requisitos para dar un "giro crítico", con enfoques renovados, hacia la historiografia del siglo XXI.

2 Ésta intenta ser una síntesis de algunas coincidencias planteadas por clistintos antores. Para no hacer demasiado extenso y cargado de referencias este escrito, no se anotan las páginas, sólo se llama al lector a consultar los textos en los volúmenes en que estas referencias están cifradas o apoyadas.
IA POSMODERNIDAD Y LA CRISIS EPISTEMOLÓgICA DE LA CIENCIA DE LA HISTORIA.

Como lo señalamos antes, la crítica a la posmodernidad y la consecuente crisis epistemológica de la historia constituyen uno de los núcleos del debate. En general, la reflexión parte de este supuesto y vuelve a él, insistentemente, para cuestionar la forma como discurre la vida actual y el regresivo y destructivo proceso de deshumanización. Varios autores coinciden en afirmar que la sociedad de la posguerra ha tendido a eliminar el pasado del centro de la vida, ha intentado escapar de los conflictos y las responsabilidades morales y políticas de la historia con un lenguaje que descansa en el cinismo, la simulación o la mentira. En este sentido, Gabrielle Spiegel plantea que el posmodernismo se corresponde con el estado psíquico característico de la segunda generación del Holocausto. A pesar de no haberla experimentado directamente, el trasfondo narrativo de la vida de esta generación ha sido la catástrofe. Su mundo se ha construido sobre lo innombrable, sobre el silencio y la negación de la memoria. ${ }^{3}$

El mundo posmoderno renuncia a la posibilidad del universalismo y opta por la violencia de los deseos locales difundidos a través de una terminología de seducción y fuerza. En nuestra época se ha instalado la ansiedad, la apatía frívola, la ausencia de todo porvenir. Su filosofía es la de la ruptura

${ }^{3}$ Spiegel, Gabrielle, "Mesa H. Revisionismo historiográfico", vol. 1, pp. 57.59. 
yeldesplazamiento, la de la indeterminación y la inmanencia que crean su propio sentido de temporalidad o intemporalidad. ${ }^{4}$

En varios trabajos se considera que la ciencia de la historia padece una crisis epistemológica. Con el fin de la creencia en los grandes paradigmas, de los grandes relatos emancipadores, la historia ha abandonado sus perspectivas teóricas, ha renunciado al proyecto de una historia globalizadora, se ha apartado de las visiones de larga duración y de la profundización del estudio de las múltiples temporalidades. Sus limitaciones para acceder al conocimiento histórico y su escasa capacidad previsiva han corrido paralelas a la multiplicación de los relatos impresionistas, del relativismo, del fraccionamiento y la atomización de la realidad. ${ }^{5}$

El paradigma estructuralista, con su capacidad para identificar los mecanismos económicos y las relaciones sociales en estructuras identificables, fue una afirmación radical de la separación entre el objeto de conocimiento histórico y la conciencia subjetiva de los actores. El paradigma cuantitativista, con suconstrucción de series y tratamientos estadísticos para formular rigurosamente las relaciones estructurales, abandonó la posibilidad de profundizar en los

4 Spiegel, Gabrielle, "Towards a theory of the Middle Ground: historical writing in the age of posmodernism", vol. I, pp. 169-176; Santana, Juan Manuel, "La historia en el fin de una época o el secuestro de Clío", vol. 1, pp. 249-259.

5 Levi, Giovanni, "Mesa C: ¿Crisis de la historia económica y social?”, vol. 1, pp. 41-42; Aguirre Rojas, Carlos y Carlos Barros, "Mesa D: El tournant critique de Annales", vol. 1, pp. $47-49$. centros problemáticos del pasado. ${ }^{6}$ Pero hoy, cualquier intento por construir un nuevo relato, dotado de coherencia interna y sentido para hacer inteligible el presente es, generalmente, tomado con escepticismo e incredulidad. En buena medida, el enfoque epistemológico ha sido sustituido por los enfoques semióticos o retóricos. Con ello se ha tendido a eliminar la diferencia entre descripción y explicación. Estos enfoques, centrados en el estatuto narrativo de la historia, ponen en riesgo -se dice- la pretensión de verdad del discurso histórico. ${ }^{7}$ La crítica del racionalismo y la "objetividad" ha sobrevaluado la condición mediadora de la percepción. Al eliminar la capacidad del lenguaje para garantizar la estabilidad esencial y fundacional del conocimiento de los problemas, el posmodernismo ha colocado en el centro de la actividad científica a la naturaleza híbrida del mundo, su discontinuidade inaprehensibilidad. Creer que la realidad está en el lenguaje, en el relato, en el cúmulo de signos proporcionados por los medios masivos de comunicación, ha puesto en riesgo la pretensión de la historia de ser un instrumento útil para el desarrollo humano. ${ }^{8}$ Tal vez lo anterior nos permita explicar por qué el problema del tiempo - a pesar de ser éste el atributo esencial de la experiencia, en tanto la relación cambio-

6 Chartier, Roger, "L'histoire aujourd'hui: doutes, défis, propositions", vol. I, pp. 119.130.

7 Vázquez García, Francisco, "Los problemas de la explicación en historia de las mentalidades", vol. li, pp. 37-52.

8 Spiegel, "Towards", op. cit. 
tiempo constituye la médula de la conciencia que el hombre adquiere de lo histórico- ha sido poco analizado o tomado en cuenta por los historiadores. ${ }^{9}$

\section{LA VITALIDAD DE LA PRODUCCIÓN HISTORIOGRÁFICA FRENTEE A LA POBREZA DE LOS MODELOS DE COMPRENSIÓN}

Algunos de los escritos coinciden en plantear cómo, frente a la vitalidad de la producción historiográfica y su capacidad de multiplicar las técnicas, los temas, la fuentes de estudio -reflejada en la aparición de enciclopedias, grandes obras colectivas, colecciones, traducciones, historias locales y regionales-, paradójicamente se han reducido las posibilidades de comprender el pasado. Los apoyos institucionales a la investigación y la multiplicación de centros de estudio han provocado una mayor rentabilidad política e ideológica a costa de la dispersión de los centros de interés y de la débil transmisión del saber histórico al conjunto de la sociedad. La microespecialización ha sido el camino de las carreras de los profesionales de la historia que compiten por acomodarse en el establishment académico. Si bien la diferencia entre ciencias duras y blandas es hoy menor-debido al abandono de los determinismos en ambas y dado que la racionalidad ya no se identifica con la

9 Aguirre Rojas, Carlos, "La larga duración en el espejo (más allá del tiempo 'vivido' y del tiempo 'expropiado')", vol. III, pp. 21-33; Arostegui, Julio, "La historia como atribución", vol. III, pp. 35- 49. certeza, ni la probabilidad con la ignorancia-, los criterios mercantilistas y operativos, ${ }^{10}$ y por tanto reduccionistas y oscurantistas, se han impuesto.

La "tecnificación" de la historia, la hiperespecialización y la débil cultura histórica, observable actualmente en la vida cotidiana, han limitado la capacidad de desarrollo de la historia. Lo que advertimos usualmente es la autorreproducción de los saberes, el reciclamiento de las viejas interpretaciones que sólo añaden nuevos fragmentos o curiosidades a una historiografía que privilegia las causas inmediatas, las racionalizaciones apresuradas, y que proporciona "verdades suficientes que no explican nada". ${ }^{11}$ Un caso ha sido el auge de la historia regional y del excesivo provincialismo que, aunque con calidades desiguales, ha tendido a trasplantar modelos a lo local, ha "descubierto mediterráneos con más frecuencia de lo deseable" o se ha conformado con la contemplación de uno mismo, de un pasado propio. ${ }^{12}$

La historia social sufrió un fuerte embate al excluir a lo grupos marginados o bien al centrarse en ellos adoptando una posición romántica, exaltadora de fantasías. Un caso representativo ha sido el de los numerosos estudios sobre el feminismo y sus posturas

10 Núñez, María Gloria, "Historia, ciencia y complejidad en los finales del siglo xx", vol. 1 , pp. $159-168$.

11 Deruette, Serge, "Pour une 'histoirc cutlsale' ", vol. I, pp. 131-141; Boureau, Alain, "Mcsa I: La historia entre la ciencia y la vulgarización", vol. 1, pp. 60.

12 Martín, José Luis, "Mesa K: la Historia en las universidades", vol. 1, pp. 62-63. 


\section{SECUENCIG}

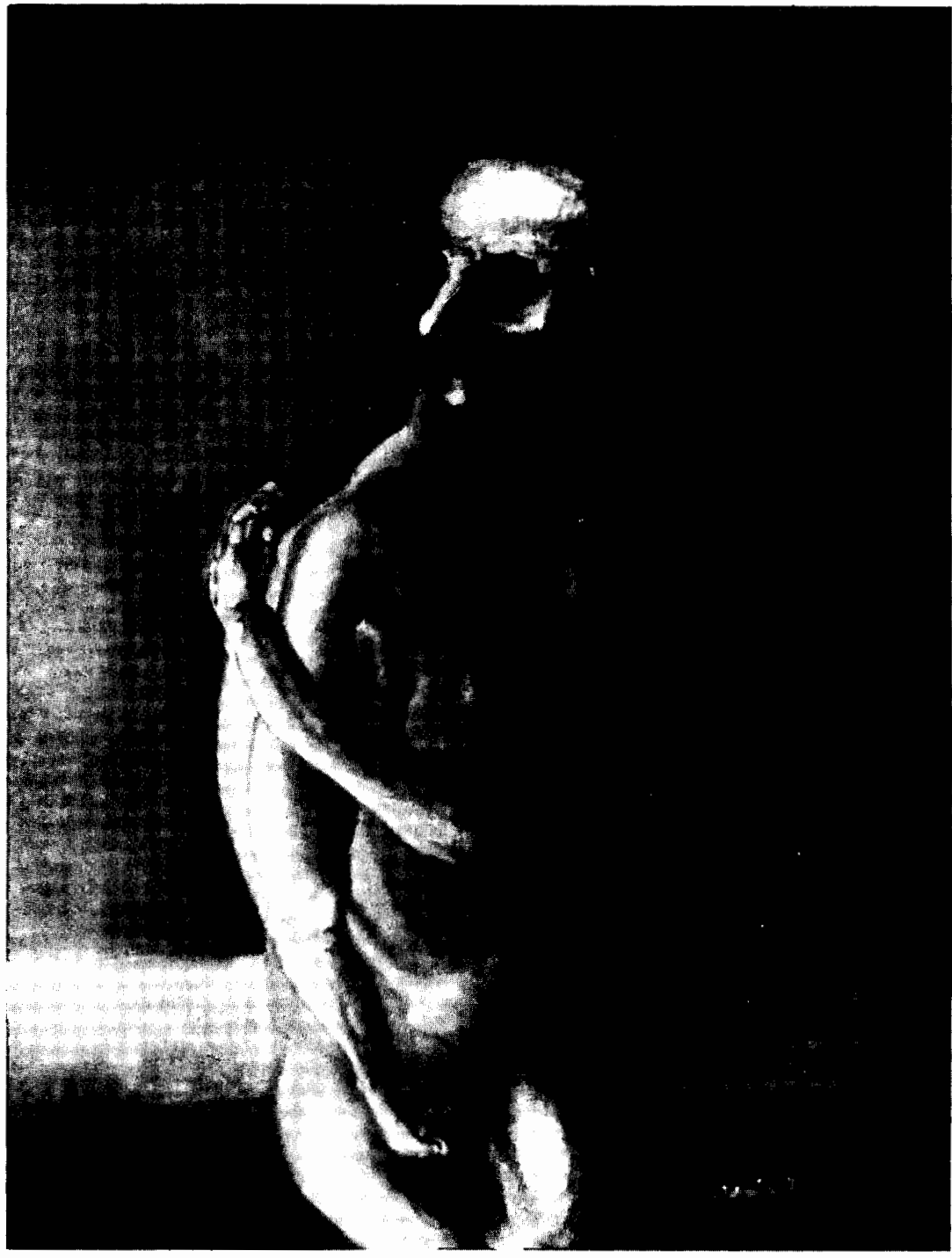

Ilustraciones de Adrián Bellón Pérez. Queda estrictamente prohibida la reproducción total o parcial de las imágenes publicadas en este número de la revista Secuencia, 39.

Las imágenes fueron contratadas y/o donadas de forma exclusiva para esta publicación. 
victimistas o triunfalistas. ${ }^{13}$ Sin embargo, la atención en las minorías y en los pueblos "sin historia" ha permitido una descripción más rica de la complejidad social. Asimismo, la relación entre individuo y grupo, la pluralidad del principio de estratificación, de los trabajos sobre diferenciación cultural y formas clientelares han permitido acercarse a una dimensión mucho más coherente de la historia social. El estudio de las instituciones ha sido importante al permitir superar lo puramente sociológico para examinar el funcionamiento de las mismas en la adopción de las normas, reglas y psicología de los comportamientos de mayor significación. ${ }^{14}$ Indudablemente, el retorno del sujeto, frente a las estructuras y modelos abstractos y a los personajes colectivos de la historia social, ha constituido una fuente de acceso al conocimiento histórico. Éste y otros "retornos", como los de la historia política, el acontecimiento, la biografia y la historia-relato, resultarán epistemológicamente adecuados cuando permitan la transformación profunda de las viejas categorías y la formulación de una nueva problemática de la historia viva. ${ }^{15}$

La historia política, revalorando los problemas del poder, la representación y las formas de dominación, ha retornado para elaborar estudios historiográficos más profundos e interdisci-

\footnotetext{
${ }^{13}$ Ruiz, Teófilo F, , "Mesa K: la Historia en las universidades", vol. I, p. 64.

${ }^{14}$ Levi, op. cit.

${ }^{15}$ Le Goff, Jacques, "Les retours dans l'historiographie francaise actuelle", vol. III, pp. 157 .
} 165. plinarios. ${ }^{16}$ Sin embargo, todavía existe un cierto abandono del análisis de las estrategias del poder político y militar en la conformación del Estado, y hay negligencia frente al problema de la religión. Además, los loables avances en el estudio de los significados simbólicos a veces han ido demasiado lejos. Cada vez se hace más una historia de símbolos, de representaciones y retórica que sobre la realidad objetiva del poder y sus dispositivoseconómicosy políticos para crear hegemonía, consenso y obedien. cia. ${ }^{17}$

Por otro lado, la crisis de la historia económica, silenciosa y discreta, resulta más inquietante que las demás. La tecnologización creciente, aplicada a esta disciplina, ha intentado explicar la problemática histórica sobre la base de microinformaciones y de la multiplicación de las lógicas estadísticas, pero ha soslayado lo esencial, o sea, la definición económica de lo social. Por este camino, la validación interna ha juzgado menos los criterios epistemológicos o técnicos que su adecuación a una problemática o paradigma dominante, y la validación externa ha carecido de un cuadro problemático de referencia. ${ }^{18}$

La "nueva historia" ha colocado a las entidades anónimas y abstractas en el lugar de los héroes. Sociedades, clases y mentalidades aparecen como cuasipersonajes dotados de personali-

${ }^{16}$ Ibid.

${ }^{17}$ Stone, Lawrence, "The future of History", vol. 1, pp. 177.189.

${ }^{18}$ Grenier, Jean Ives y Alejandro Tortorcllo Villaseñor, "Mesa C: ¿Crisis de la historia económica y social?", vol. I, pp. 43-46. 
dad propia. El carácter autoexplicativo de la narrativa se opone a la capacidad explicativa de un conocimiento controlable y verificable. Toda historia narrativa o estructural es construida hoy a partir de fórmulas que gobiernan la producción de los relatos. De este modo, el discurso se sustrae de la relación activa entre literatura y sociedad y no se le dota de un estatuto científico y de significación. ${ }^{19} \mathrm{El}$ retorno del sujeto, de la historia biográfica, la historia-relato y el acontecimiento resultarán positivos cuando mantengan un espíritu más científico que literario y se propongan ser esas condensaciones cargadas de significación, sentido y función, capaces de recuperar la dimensión global; de relacionarse con las realidades históricas de ritmos más lentos, y de apartarse de la frivolidad, de los simple o superficial, de lo anacrónico y lo anecdótico. ${ }^{20}$

EL GIRO CRÍTICO Y LA RENOVACIÓN DE LOS ENFOQUES HISTORIOGRÁFICOS DEL SIGLO XXI

En el conjunto de la obra se destaca un acusado interés por renovar los enfoques historiográficos, por abrir espaciosadecuados para emprender el "giro crítico" de la ciencia de la historia. La recuperación del sentido histórico de la teoria social marxista, de la capacidad de los primeros Annales para comprender la complejidad humana en sus dimensiones y temporalidades globales, de las posibilidades de

${ }^{19}$ Chartier, $o p$. cit.

${ }^{20}$ Le Goff, $o p$. cit. adentrarse por los caminos de la microhistoria, de la nueva historia cultural y de compenetrarse con la "lógica social de los textos" 21 son algunas de las alternativas que se ofrecen para conformar el nuevo cuerpo teóricometodológico que posibilite restablecer la función crítica de la historia en el centro del conocimiento humano y el futuro de la sociedad.

La utilización de las propuestas de Marx en la investigación histórica fue un problema político, un problema del discurso de la legitimación del presente. El Marx simplificado por la academia, el estructural-marxismo, el marxismo-leninismo y el socialismo real tendieron a imponer un marxismo uniformizado que eliminó sus elementos reflexivos y lo redujo a definiciones de conceptos, categorías y leyes eternas. La obra de Marx es, por el contrario, variada, contradictoria y ambivalente. Su racionalismo crítico, su método de análisis de las fuentes, su búsqueda de los fundamentos de localización de los centros-problema o de conflicto, constituyen todavía el sistema teórico más acabado y realista para comprender la dimensión histórica del mundo social. Su idea fundamental de la relación entre la organización de la producción y la organización social, sus teorías sobre la renta de la tierra, la lucha de clases, la violencia y la explotación en el mundo capitalista representan un aporte indispensable para todo análisis racional de la evolución de las sociedades. ${ }^{22}$

21 Spiegel, "Towards", op. cit.

${ }^{22}$ Wicklham, Chris, Bolivar Echeverria, Alain Guerreau y Juan Trias Bejarano, "Mesa B: Marxismo e historia en los años 90", vol. 1, pp. 69-91. 
Para que la historiografia supere la actual encrucijada tendrá que interesarse nuevamente por el debate teórico, dialogar con el marxismo que le dio forma y volver a concederle importancia a la interpretación, la síntesis histórica y la interdisciplinariedad. ${ }^{23}$ Por este camino, en 1989, la revista francesa Annales, en su cuarta etapa, abrió el debate hacia el tournant critique, hacia la recuperación del proyecto de Bloch, Febvre y Braudel y su intento de profundizar y renovar la exploración de los tiempos históricos, la larga duración y la historia social. ${ }^{24}$ Recuperar el sentido que los primeros Annales le confirieron a la historia significa tener presente que el análisis estructural no es tautología. Cada momento, cualquiera que sea su duración, combina una pluralidad de tiempos sociales a sus ritmos y a su propia escala. La explicación es el resultado de un proceso de identificación de las temporalidades múltiples, y las curvas que rinden cuenta de las fluctuaciones son sólo un instrumento de acceso al proceso histórico global. ${ }^{25}$ Los acontecimientos surgidos de la inmediatez son relativizados por los tiempos largos en que se inscriben. Son éstos los que modelan y determinan lo singular, innovan y marcan la evolución. Bajo estos supuestos, la historia causal debe apuntar hacia distintas direcciones y diversos niveles de aprehensión de los

${ }^{23}$ Barros, Carlos, "La historia que viene", vol. I, pp. 95-117.

24 Aguirre Rojas, Carlos y Carlos Barros, "Mesa D:", op. cit.

25 Lepetit, Bernard, "La societé comme un tout", vol. I, pp. 147-158. procesos. El estudio de la coyuntura y de los episodios casi moleculares de la transformación histórica, deben tomarse como el marco de referencia para sistematizar los fenómenos y comprender la multicausalidad a través de las determinaciones concretas que los producen. ${ }^{26}$

El tipo de relatos historiográficos de la "nueva historia" no mantiene ni las mismas construcciones ni las mismas figuras que los grandes relatos estructuralistas de la historia global o los relatos estadísticos de la historia serial. Sin embargo, será preciso repensar las propiedades específicas de unos y otros relatos para integrar un discurso que sea comprensivo en sí mismo; será preciso recordar que lo colectivo es el producto de una construcción dada y provisoria, de un acuerdo activo, temporal e inestable, que depende de las características de la situación del momento. La estabilidad y duración de estas construcciones colectivas se renuevan ante la diversidad de las fuerzas movilizables y la heterogeneidad de los productos efectivamente movilizados. ${ }^{27}$ Entonces, es necesario analizar la forma como la secuencia breve se monta en lo general. El juego abierto es evitartododeterminismo funcionalista o estructuralista. Ante la notoria tendencia a la "ghettización" de la historia (en historia económica, social, política, etc.) que termina en exposiciones monocausales, el gran reto de los historiadores será entrelazar la historia social y económica con la historia de la cultura, y añadirle las

\footnotetext{
26 Deruette, op. cit.

${ }^{27}$ Lepetit, op. cit.
} 
vicisitudes de la guerra, el poder politico, la alta política, la religión... Darle un espacio a to individual excepcional, romper las barreras artificiales entre las disciplinas, la trivialización y la fragmentación son parte de este mismo reto. ${ }^{28}$

Los acuerdos que establecen los actores sociales son susceptibles de presentar una figura particular, pero se inscriben siempre como una variación localizada en el desarrollo más largo de las convenciones dominantes a las que se tienen que ajustar. Las normas, los valores y las convenciones sociales dan lugar a un conjunto de representaciones colectivas que participan y presuponen cuerpos organizados, instituciones y reglas del derecho. Aparecen como un cuadro heredado del pasado que encierra y moldea las prácticas individuales y colectivas; es lo que les da fuerza de duración. Las generalidades históricas se construyen y deforman, se organizan sobre tensiones temporales dispuestas en regímenes de historicidad particular. Es bajo estos principios que importa preguntarse por los modelos que le dan valor a la historia y a la práctica de la historia. ${ }^{29}$ 'Tomando en consideración estos supuestos, el término cultura se ha extendido para abarcar un rango más amplio de actividades artísticas y de la cultura material, de lo escrito y lo oral, del drama y el ritual. La nueva historia cultural se ha desplazado de historia social de la cultura a historia cultural de la sociedad. El estudio de la diversidad y de la interacción

28 Stone, op. cit.

29 Lepetit, op. cit. cultural significa comunicación e intercomunicación, conquista e invasión, robo, creación, destrucción, interpretacióny desinterpretación, apropiación y resistencia. Significa, también, superar confusiones conceptuales elementales como, por ejemplo, las que se dan en el uso de los términos aculturación, apropiación, recepción, asimilación, acomodación, intercambio, sincretismo, hibridación, mestización o criollización. ${ }^{30}$

Los sistemas de relaciones que organizan el mundo social, reales, aunque no tangibles o visibles, están fuertemente unidos a la diversidad de los objetos y al papel que juegan los individuos en la construcción de las relaciones sociales. Para conocer las normas colectivas y las estrategias singulares, la microhistoria italiana y la española han retornado al sujeto bajo modelos interaccionistas o etnometodológicos. Radicalmente diferente de la monografia tradicional, la microhistoria intenta reconstruir, a partir del estudio intensivo de objetos bien delimitados, la manera como los individuos producen el mundo social. La microhistoria penetra en los intersticios del análisis serial para acceder a la experiencia individual que resulta inaccesible en los estudios de agregados. La normalidad de las situaciones excepcionales validan las señales contrarias a los problemas que representan. Al analizar las racionalidades y estrategias que orientan las obras de las comunidades, parentelas, familias e individuos; al indicar las diferencias

\footnotetext{
${ }^{30}$ Burke, Peter, "Varieties of cultural history", vol. II, pp. 175-177.
} 
y discordancias entre los sistemas de normas de una sociedad y en el interior de cada una de ellas; al destacar las reglas impuestas y sus usos inventados, su poder social, sus necesidades económicas y sus diversos niveles de acceder a la información, la microhistoria dota a la historia social de nuevos objetos para la comprensión del pasado. En los trabajos producidos por esta corriente se puede observar, entre otras cosas, cómo un sistema normativo no está asido a una estructura y no elimina la posibilidad de los distintos agentes sociales de manipular, negociar o interpretar las reglas. ${ }^{31}$ Más atenta a la representación de los papeles sociales que a las estructuras y al proceso de estructuración social que se genera por su interacción, la microhistoria saca a Ia luz la capacidad interpretativa de los actores, propone el modelo de un individuo activo y racional en un universo caracterizado por las incertidumbres y los contratos que dependen de la distribución desigual de las capacidades individuales de acceso a la información. ${ }^{32}$ De este modo, la microhistoria provee todo un cuerpo de construcción formal, de instrumental conceptual que pondera, de la realidad pasada, aquello que no habíamos sabido captar en toda su complejidad. ${ }^{33}$

Flgiro lingüístico o desafio semiótico ha buscado establecer distinciones funcionales entre texto y contexto, entre realidades sociales y expresiones simbólicas, entre discurso y prácticas no

\footnotetext{
31 Chartier, op. cit

32 Lepetit, op. cit.

33 Levi, op. cit.
}

discursivas. Sin embargo, resulta absurdo reducir las prácticas constructivas del mundo social a los principios que dirigen los discursos, dado que la presencia de intereses e intenciones plasmados en los discursos, está, en sí misma, determinada socialmente. Son las posiciones y propiedades socialmente objetivas, exteriores al discurso, las que caracterizan a los grupos, comunidades o clases y, así como hay una lógica que gobierna la producción del discurso, hay una lógica práctica que regula las conductas y las acciones. En consecuencia, el objetivo fundamental de la crítica y la interpretación de las fuentes es encontrar el sentido que los actores sociales le confieren a sus prácticas y discursos. Este sentido reside en la tensión entre la capacidad de inventiva de los individuos y las comunidades, y las normas y las convenciones que los limitan desde posiciones contrarias o dominantes y que marcan lo que es posible pensar y hacer. El trabajo del historiador debe centrarse entonces, por una parte, en las relaciones sociales complejas y variables, en su modo de organización y de ejercer el poder y, por otra, en las configuraciones sociales que hacen posible esa forma política o que son engendradas por ella. Los individuos están unidos por dependencias recíprocas, perceptibles o invisibles, entre las formas de afectividad y racionalidad. Estas dependencias funcionan y se estructuran de un modo particular. Pensar históricamente es tener la capacidad de poder explicar las formas y prácticas culturales de los modos de pensar y creer, de fijar el sentido de las obras, su fuerza y violen- 
cia simbólica, de advertir los tipos de experiencia con lo cotidiano y con la sumisión. Bajo estas premisas, la "lógica social del texto" - una categoría de análisis presentada por Gabrielle Spiegel-propone la aplicación de una perspectiva dual en la investigación de los textos que, por una parte, los ubique en el espacio social general que ocupan como producto de un particular mundo social, como agentes activos en ese mundo y que, por otra, destaque sus propias características discursivas como $\log o s$, con su propio artefacto de literación compuesto por el lenguaje y con su propio análisis literario de carácter formal. ${ }^{34}$ Por un camino similar, la propuesta de Peter Aronsson, de una historia conceptual como perspectiva posible para renovar la interpretación histórica, resulta -desde nuestro punto de vista-particularmente interesante, al analizar cómo en la problemática de los actores sociales y la estructura histórica que los atraviesa se van moldeando y transformando los conceptos de comunidad y sociedad, así como su uso y función en una cultura determinada. 35

La superación de la crisis epistemológica reclama un nuevo paradigma capaz de incorporar una historia en continuo debate. Acompañando a muchos de los escritos que se presentaron en este congreso, pero, sobre todo, acompañando al "giro crítico"

${ }^{34}$ Spiegel, op. cit.

${ }^{35}$ Aronsson, Peter, "The possibilities of conceptual history 'from above' and from below: reflections on the concept of samhälle 'society' in Sweden, 1700 to 1990", vol. II, pp. 237-260. -a las propuestas teóricas para recuperar al Marx reflexivo y crítico, a los primeros Annales y su sintesis global, a la microhistoria y la nueva historia cultural y para aplicarle una lógica de carácter social a los textos-, ya ha aparecido un conjunto de trabajos historiográficos que intentan superar la incertidumbre de la posmodernidad. El éxito de la "historia que viene" dependerá de su capacidad para generar y aplicar estrategias globales de investigación, de su capacidad para reforzar la cooperación de la historia con otras ciencias. El futuro de la historia está condicionado por lo que se preocupe la historia por avanzar en su unificación interna como ciencia de los hombres en el tiempo, en lo que se preocupe por el futuro ${ }^{36}$ y la realidad presente.

Desde el psicoanálisis sabemos que la represión de toda molestia, si no se confronta, volverá mañana cargada de autodestrucción. La historia tiene como uno de sus objetivos básicos desenmascarar las legitimaciones en que se sustenta el poder y mantener una postura crítica frente a los dogmas y las injusticias. El conocimiento crítico es el único camino útil para la acción. Abandonar la curiosidad, la duda y la intención de acceder a la verdad, es dejarle el campo libre a las molestias, las falsificaciones, las simulaciones, al cinismo y a todas las formas posibles de tergiversación de la memoria. ${ }^{37}$

Ciudad de México, febrero de 1997

36 Barros, "La historia", op. cit.

37 Chartier, op. cit. 


\section{SECUENCIG}

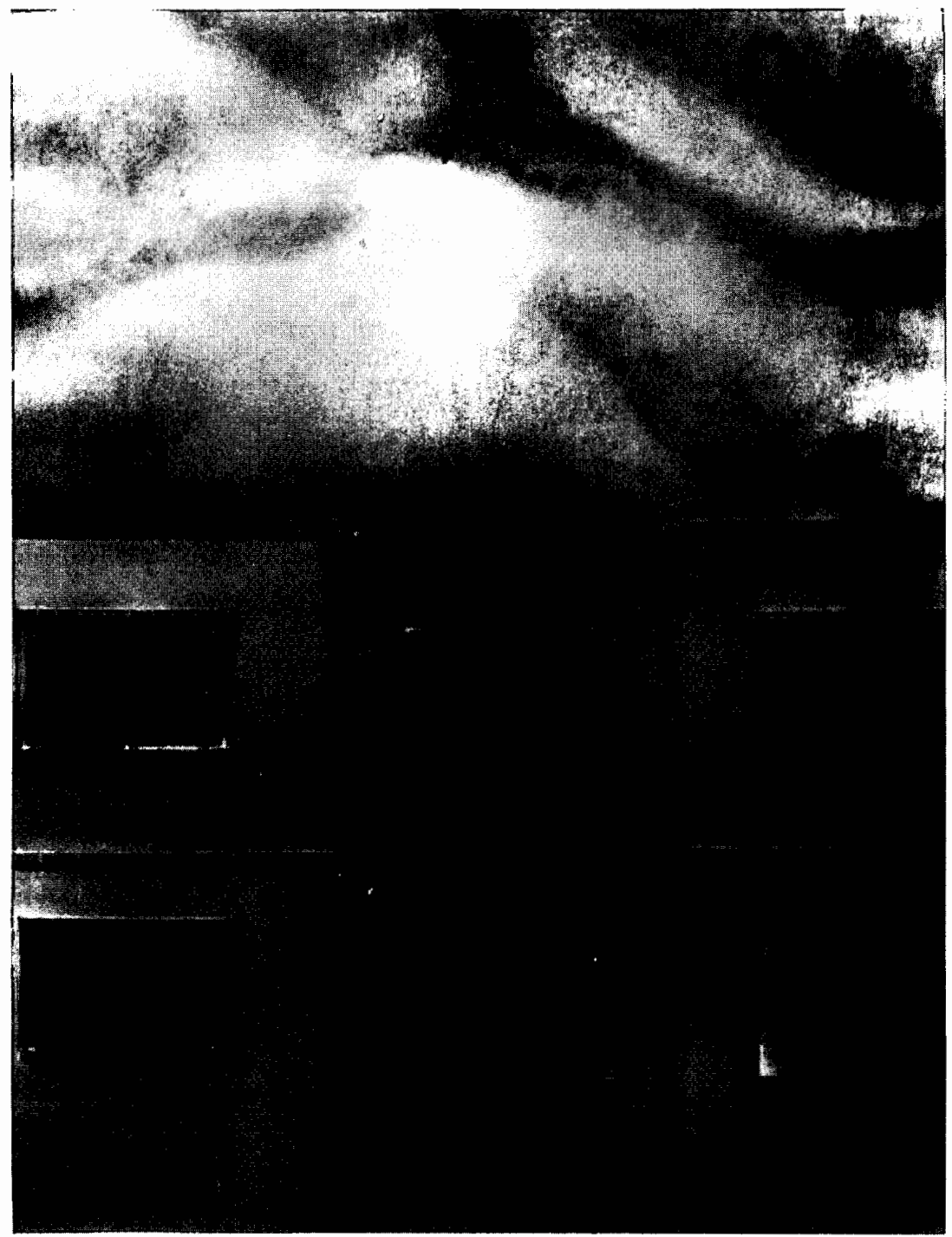

178 